\title{
INSULINOMAS DO PÂNCREAS: diagnóstico e tratamento
}

\author{
Franz Robert APODACA-TORREZ, Tarcisio TRIVIÑO, \\ Edson José LOBO, Alberto GOLDENBERG e Antônio FIGUEIRA*
}

RESUMO - Racional - O insulinoma é uma neoplasia que pertence ao grupo de tumores neuroendócrinos do pâncreas; embora raro, é o mais freqüente entre eles. Objetivo - Avaliar os resultados clínico e imunohistoquímico de doentes com insulinoma de pâncreas submetidos a tratamento cirúrgico. Pacientes e Métodos - Foram detalhados o quadro clínico, exames laboratoriais e de imagem, dando ênfase aos aspectos cirúrgicos, complicações e acompanhamento, a médio e longo prazos, de 12 doentes portadores de insulinoma. A cirurgia foi indicada para todos, com base nas evidências clínicas e laboratoriais de hipoglicemia e hiperinsulinemia. Resultados - Em sete doentes conseguiu-se a localização prévia da lesão; em cinco, sua localização foi identificada durante a cirurgia mediante palpação e através do ultra-som intra-operatório. O procedimento mais freqüentemente utilizado foi a ressecção pancreática em oito doentes. A complicação cirúrgica mais freqüente foi a fístula pancreática, observada em sete doentes. Dois apresentaram tardiamente diabetes mellitus. Não houve mortes na presente casuística. Conclusão - Na totalidade dos doentes obteve-se a reversão clínica dos sintomas, caracterizada pelo desaparecimento da tríade de Whipple, além de normalização ou aumento dos níveis de glicemia, quando comparados aos valores do pré-operatório.

DESCRITORES - Insulinoma, cirurgia. Neoplasias pancreáticas.

\section{INTRODUÇÃO}

Os insulinomas do pâncreas são neoplasias das células beta das ilhotas pancreáticas, caracterizados pela produção excessiva de insulina, manifestada por sintomas neurovegetativos e neuroglicopênicos secundários à hipoglicemia. São causas de hiperinsulinismo orgânico: o adenoma benigno das células beta do pâncreas, a microadenomatose difusa das ilhotas pancreáticas, a neoplasia maligna das ilhotas pancreáticas e a nesidioblastose ${ }^{(9)}$. Embora seja uma neoplasia rara, o insulinoma constitui o mais freqüente dos tumores neuroendócrinos do pâncreas ${ }^{(19)}$. Este tipo de neoplasia foi relatado inicialmente por NICHOLLS ${ }^{(31)}$, em 1902, e WILDER ${ }^{(51)}$, em 1927; entretanto, foi a partir de WHIPPLE e FRANTZ ${ }^{(48)}$, que se iniciou o melhor conhecimento da doença. A dificuldade diagnóstica ${ }^{(7,52)}$ e os sintomas neuropsiquiátricos desta doença freqüentemente levam a erros no diagnóstico ${ }^{(39)}$. Em nosso meio, existem poucas publicações a respeito dessa neoplasia ${ }^{(1,2,14,26,32)}$.
O tratamento cirúrgico dos insulinomas constitui a melhor alternativa para a terapêutica desta doença e o acompanhamento a longo prazo merece melhor atenção ${ }^{(12)}$.

O presente estudo tem como objetivo analisar as características clínicas, cirúrgicas e anatomopatológicas de uma série de doentes portadores de insulinoma de pâncreas tratados na Disciplina de Gastroenterologia Cirúrgica da Universidade de São Paulo - Escola Paulista de Medicina - UNIFESP - EPM.

\section{CASUÍSTICA E MÉTODOS}

No período de janeiro de 1986 a dezembro de 2001, foram estudados 12 doentes consecutivos, portadores de insulinoma do pâncreas submetidos a tratamento cirúrgico. Sete eram do sexo feminino e cinco do sexo masculino; suas idades variavam de 17 a 74 anos, com média de 51 anos. O quadro clínico caracterizou-se, fundamentalmente, pelos sintomas neuropsiquiátricos, sendo os mais freqüentes: convulsões, sonolência, sudorese, alterações da personalidade e do comportamento (Tabela 1).

Trabalho realizado na Disciplina de Gastroenterologia Cirúrgica do Departamento de Cirurgia da Universidade Federal de São Paulo - Escola Paulista de Medicina, São Paulo, SP. Endereço para correspondência: Dr. Franz R. Apodaca-Torrez - Rua Maracá, 266 - ap. 131 - 04313-210 - São Paulo, SP. e-mail: apodaca@uol.com.br

* In memoriam 
TABELA 1 - Freqüência dos sintomas e sinais encontrados

\begin{tabular}{lcc}
\hline SINTOMAS E SINAIS & $\mathbf{n}$ & $\mathbf{\%}$ \\
\hline Convulsões & 7 & 58,3 \\
Alteração da personalidade & 5 & 41,6 \\
Sonolência & 5 & 41,6 \\
Sudorese & 6 & 50 \\
Aumento de peso & 7 & 58,3 \\
Distúrbios visuais & 5 & 41,6 \\
Liberação de esfíncter & 6 & 50 \\
Perda de consciência & 3 & 25 \\
Tontura & 3 & 25 \\
Anorexia & 3 & 25 \\
Coma & 3 & 25 \\
Alteração de conduta & 2 & 16,6 \\
Perda de peso & 2 & 16,6 \\
Confusão mental & 2 & 16,6 \\
Afasia e hemiplegia & 1 & 8,3 \\
Formigamento & 2 & 16,6 \\
Fraqueza muscular & 1 & 8,3 \\
Amnésia transitória & 1 & 8,3 \\
Cefaléia & 2 & 16,6 \\
Taquicardia & 1 & 8,3 \\
Náuseas e vômitos & 1 & 8,3 \\
\hline
\end{tabular}

O tempo decorrido entre o aparecimento dos sintomas e a procura por atendimento médico variou de 1 a 14 anos. Nove doentes apresentavam melhora dos sintomas com as refeições e em 11 deles os sintomas desapareciam totalmente com a administração de glicose endovenosa. A tríade de Whipple característica foi observada em 11 doentes e todos apresentavam três ou mais sintomas.

A dosagem de glicemia em jejum foi o principal método de laboratório na investigação destes doentes, mostrando níveis iguais ou inferiores a $50 \mathrm{mg} / \mathrm{dL}$ em 11 deles (média de 41,0 mg/dL). Somente um doente apresentou níveis de $58 \mathrm{mg} / \mathrm{dL}$. O teste do jejum prolongado foi realizado em todos os doentes, mostrando resultados positivos em todos. A dosagem da insulina sérica em jejum foi realizada em 10 doentes, com resultados acima do limite superior da normalidade em todos eles (média de 80,47); nestes doentes foi aplicada a relação insulina/glicemia proposta por FAJANS e FLOYD ${ }^{(9)}$, mostrando em todos valores superiores a 0,3 (média de 2,02).

Entre os métodos de imagem, a ultra-sonografia abdominal identificou imagem hipoecogênica na topografia de pâncreas em dois $(16,6 \%)$ doentes; a tomografia axial computadorizada mostrou lesão na topografia pancreática em três $(25 \%)$, e em um caso este exame sugeriu extensão hepática da doença. A arteriografia seletiva do tronco celíaco foi utilizada em nove doentes, sendo que em dois (22,22\%) revelou lesão hipervascularizada na topografia pancreática. A ecoendoscopia foi realizada em dois doentes, mostrando em ambos nódulo hipoecóico. Em dois doentes da série também foi realizado o cateterismo transparietal da veia porta com dosagem seriada de insulina, revelando valores elevados. Com base na caracterização da hipoglicemia, secundária ao hiperinsulinismo de origem pancreática, e tendo sido localizada ou não a lesão, em todos os doentes da presente série foi indicado o tratamento cirúrgico. A abordagem foi feita mediante incisão transversa supra-umbilical ampla, revisão sistematizada da cavidade, exposição e palpação minuciosa da glândula. Em três doentes foi realizada ultra-sonografia intra-operatória com transdutor de $5 \mathrm{MHZ}$.

Em todos os doentes foi realizada a monitorização da glicemia durante o ato operatório. Uma vez localizado o insulinoma, procedeuse a enucleação ou ressecção pancreática, considerando a localização da lesão, multiplicidade, bem como as condições clínicas do doente. $\mathrm{O}$ espécime ressecado foi submetido a exame histopatológico e estudo imunohistoquímico mediante o método da Strepto-Avidina-BiotinaPeroxidase. No que concerne à análise estatística, foram realizados o teste $t$ pareado para comparar dois grupos de informações com nível de mensuração numérica, e o teste $\mathrm{G}$ de Cochran para comparar a incidência de três ou mais grupos de características em uma amostra pareada.

\section{RESULTADOS}

Em sete doentes foi possível localizar a neoplasia no préoperatório. Uma vez realizada a abordagem da retrocavidade e exposição completa do pâncreas, manobra de Kocher e palpação bidigital cuidadosa do pâncreas, foi possível localizar todas as lesões que apresentavam consistência fibroelástica.

\section{Caracterização das neoplasias}

Em oito doentes foi encontrada lesão única e em quatro, lesões múltiplas. A análise conjunta dos doentes permitiu coletar 16 lesões distribuídas no pâncreas da seguinte maneira: corpo, seis (37\%), cauda, sete $(43,7 \%)$ e porção cefálica, três $(18,7 \%)$. O tamanho das neoplasias variou entre 0,5 e $4 \mathrm{~cm}$. A ultra-sonografia intra-operatória realizada em três doentes confirmou os achados da palpação. Em dois casos foram realizadas biopsias por congelação, devido à presença de gânglios peripancreáticos com aparente comprometimento. Uma delas mostrou comprometimento neoplásico maligno.

A monitorização da glicemia antes, durante e após o ato cirúrgico evidenciou a reversão dos níveis de hipoglicemia do pré-operatório para níveis de hiperglicemia após ressecção da neoplasia. 


\section{Ressecção das lesões}

Foi realizada a enucleação do insulinoma em quatro doentes e pancreatectomia caudal ou corpo caudal em oito doentes, associada ou não à esplenectomia (Tabela 2).

TABELA 2 - Procedimentos cirúrgicos realizados

\begin{tabular}{lcc}
\hline Procedimentos cirúrgicos & n & $\mathbf{\%}$ \\
\hline Pancreatectomia corpocauldal & 2 & 16,6 \\
Pancreatectomia corpocaudal e esplenectomia & 4 & 33,3 \\
Pancreatectomia caudal e esplenectomia & 1 & 8,3 \\
Pancreatectomia caudal, esplenectomia e enucleação & 1 & 8,3 \\
Enucleação & 4 & 33,3 \\
Total & 12 & 100,0 \\
\hline
\end{tabular}

\section{Níveis de glicemia}

Em todos os doentes, a dosagem de glicemia realizada no $1^{\circ}$ dia de pós-operatório, revelou níveis superiores àqueles observados por ocasião da caracterização da hipoglicemia, mostrando níveis que variavam de 130 a $280 \mathrm{mg} / \mathrm{dL}$, (média de 201,5 mg/dL) $P<0,001$ *.

\section{Estudo anatomopatológico}

Todas as neoplasias eram bem delimitadas e de consistência fibroelástica; a análise histológica revelou que 11 (91,7\%) doentes apresentavam insulinoma benigno e $1(8,3 \%)$ era portador de insulinoma maligno. Para a imunohistoquímica foram testados os seguintes marcadores tumorais: cromogranina, insulina, gastrina, somatostatina e glucagon. Houve imunocoloração intracitoplasmática, de forma granular, difusa para cromograninas na maioria das células tumorais em todos os casos estudados. A imunoexpressão para insulina foi variável na neoplasia, quer em número de células imunocoradas, quer na intensidade da imunorreação, porém a grande maioria das células neoplásicas imunocorou. Em 10 doentes o estudo revelou tratar-se de insulinomas pluri-hormonais e somente em dois mono-hormonais (Tabela 3).

\section{Complicações}

Entre as complicações abdominais, a fístula pancreática foi a mais freqüente, observada em sete (58,3\%) doentes; o diagnóstico da fístula baseou-se na exteriorização de secreções pelo dreno de Penrose, com níveis de amilase superiores a $1.000 \mathrm{UI} / \mathrm{mL}$. O tratamento da fístula foi conservador. Um dos doentes evoluiu com abscesso intracavitário, tratado por laparotomia e drenagem no $22^{\circ}$ dia de pós-operatório. A média de permanência hospitalar no pós-operatório foi de 16,1 dias (variação de 9 a 25); houve infecção da ferida operatória em dois doentes. Em 10 (83,3\%) doentes observou-se hiperglicemia transitória cujos valores normalizaram-se num período que variou de 2 a 21 dias.

Os níveis de glicemia no pós-operatório tardio estão detalhados na Tabela 4.

Dois doentes desenvolveram diabetes mellitus (16,6\%): um controlado com o uso de hipoglicemiante oral, o outro com insulina $\mathrm{NPH}$ em doses diárias de 22 UI. Dois doentes morreram de

TABELA 3 - Resultados da imunohistoquímica para marcadores hormonais dos insulinomas por caso estudado

\begin{tabular}{|c|c|c|c|c|c|}
\hline PACIENTES & Cromogranina & Somatostatina & Glucagon & Gastrina & Insulina \\
\hline 1 & + & + & - & - & + \\
\hline 2 & + & + & - & - & + \\
\hline 3 & + & + & - & + & + \\
\hline 4 & + & + & + & + & + \\
\hline 5 & + & + & - & - & + \\
\hline 6 & + & + & + & + & + \\
\hline 7 & + & - & - & - & + \\
\hline 8 & + & + & - & + & + \\
\hline 9 & + & + & + & + & + \\
\hline 10 & + & + & - & + & + \\
\hline 11 & + & + & - & - & + \\
\hline 12 & + & - & - & - & + \\
\hline TOTAL & 12 & 10 & 3 & 6 & 12 \\
\hline
\end{tabular}

$+=$ Imunorreação para o hormônio pesquisado na neoplasia

- = Ausência de imunoexpressão hormonal pelas células neoplásicas

Teste $\mathrm{G}-$ Cochran, $P=0,0004 *$ (Insulina $=$ Somatostatina $>$ Gastrina $>$ Glucagon $)$ 
TABELA 4 - Comparação dos valores da glicemia em jejum do pré-operatório com os do pós-operatório tardio mg/dL

\begin{tabular}{|c|c|c|c|}
\hline PACIENTES & Glicemia pré-operatória & Glicemia pós-operatória & Tempo pós-operatório (meses) \\
\hline 1 & 36 & 109 & 48 \\
\hline 2 & 28 & 132 & 02 \\
\hline 3 & 34 & 231 & 60 \\
\hline 4 & 45 & 107 & 60 \\
\hline 5 & 45 & 102 & 12 \\
\hline 6 & 58 & 130 & 12 \\
\hline 7 & 38 & 80 & 24 \\
\hline 8 & 44 & 117 & 12 \\
\hline 9 & 43 & 101 & 12 \\
\hline 10 & 50 & 45 & 18 \\
\hline 11 & 34 & 140 & 41 \\
\hline 12 & 37 & 127 & 12 \\
\hline
\end{tabular}

Teste $t$-pareado, $P=0,0030^{*}$

complicações não relacionadas ao procedimento cirúrgico: um de broncopneumonia 8 anos após a cirurgia, o outro por acidente vascular cerebral, 6 anos depois.

$\mathrm{O}$ único doente com diagnóstico de insulinoma maligno, inicialmente evoluiu com diabetes mellitus. Um ano após a cirurgia, novamente apresentou quadro clínico de hipoglicemia, sendo confirmada a recidiva da neoplasia no remanescente pancreático, além de disseminação hepática da doença.

\section{DISCUSSÃO}

O insulinoma é, sem dúvida, o mais freqüente dos tumores neuroendócrinos do pâncreas, representando $70 \%$ de todos eles ${ }^{(37)}$; séries iniciais reportam distribuição semelhante entre o sexo feminino e o masculino, com $54 \%$ e $46 \%$, respectivamente ${ }^{(22)}$; outras relatam seu predomínio no sexo masculino ${ }^{(19)}$. Grandes casuísticas mencionam discreta prevalência no sexo feminino $(60 \%)$ sobre o masculino $(40 \%)^{(21,35,43)}$. Na presente série, a incidência foi de $58,3 \%$ para o sexo feminino e $41,7 \%$ para o masculino. A idade dos pacientes incidiu com maior freqüência entre a $3^{\text {a }}$ e a $7^{\text {a }}$ décadas, dados compatíveis com os da literatura, embora existam relatos da doença nos extremos da vida ${ }^{(16,27)}$.

No quadro clínico do insulinoma, desde os primeiros relatos ${ }^{(22,51)}$ até os trabalhos mais recentes ${ }^{(26,46,53)}$, chamam a atenção os sintomas neuropsiquiátricos, bem como a inespecificidade dos sintomas gastrointestinais. KAVLIE e WHITE ${ }^{(19)}$ mostraram que $50 \%$ dos pacientes portadores de insulinoma, antes de terem diagnosticada a doença neuroendócrina, haviam sido submetidos a tratamento neuropsiquiátrico. Nesta casuística tal fato aconteceu em $75 \%$ dos pacientes.
O marco histórico no diagnóstico desta doença é a descrição da tríade, caracterizada por sintomas neuroglicopênicos, hipoglicemia inferior a $50 \mathrm{mg} / \mathrm{dL}$ e reversão dos sintomas com a administração de glicose ${ }^{(49)}$. Apesar de não ser patognomônica dos insulinomas, a tríade de Whipple é, ainda, a melhor forma de se orientar no diagnóstico da hipoglicemia induzida pelo hiperinsulinismo ${ }^{(17)}$. Na casuística presente, a tríade foi observada em $91,6 \%$ dos pacientes, constituindose na principal manifestação clínica da doença. A confirmação da hipoglicemia, mediante dosagem da glicemia em jejum, é o primeiro passo e considerado da maior importância pela literatura médica para o diagnóstico inicial do insulinoma ${ }^{(49,51)}$. Este foi o exame que desencadeou a investigação do hiperinsulinismo em todos os pacientes desta série. Da mesma forma, o teste do jejum prolongado ainda é amplamente aceito, com resultados significativos no diagnóstico da hipoglicemia secundária ao insulinoma. No estudo multicêntrico realizado por STEFANINI et al. ${ }^{(43)}$, de um total de 149 autores, o teste do jejum prolongado foi empregado por 109 deles, com positividade para o diagnóstico da doença de $95 \%$ e, quando associado à dosagem da insulina sérica por métodos de radioimunoensaio, melhora consideravelmente o diagnóstico laboratorial do insulinoma ${ }^{(26,29)}$. Na presente casuística mostrou-se positivo na maioria dos pacientes nas primeiras 12 horas. $O$ índice insulinemia/ glicemia $(\mathrm{I} / \mathrm{G})^{(9)}$ sugere o diagnóstico de insulinoma quando seus valores atingem níveis superiores a 0,3 . Este índice foi obtido em 10 pacientes desta casuística, atingindo valores significativos em todos.

A determinação topográfica da neoplasia nos períodos préoperatório e perioperatório, vem sendo dos aspectos mais estudados nos últimos anos e considerada para alguns o padrão-ouro para o tratamento do insulinoma ${ }^{(44)}$. Esta localização tem resultados muito variáveis na literatura médica, sendo os melhores índices conseqüência 
do aprimoramento dos métodos de laboratório e, principalmente, do diagnóstico por imagem ${ }^{(35)}$.

Entre os métodos de imagem não-invasivos utilizados no diagnóstico dos insulinomas, destacam-se a ultra-sonografia, a tomografia computadorizada e a ressonância magnética. A ultrasonografia abdominal, considerada método atraente e de simples execução, tem na posição retroperitonial do pâncreas seu principal obstáculo, além de ser um exame operador dependente. Como conseqüência, têm sido reportados resultados muito variáveis ${ }^{(10,20)}$, chegando sua positividade a oscilar de $0 \%(1), 28,1 \%{ }^{(26)}$, até $63 \%^{(13)}$. $\mathrm{Na}$ presente casuística, a ultra-sonografia mostrou-se efetiva na localização da neoplasia, em apenas 16,6\% das vezes. A tomografia computadorizada é método freqüentemente citado como de valor no diagnóstico das neoplasias do pâncreas, com seus resultados variáveis, dependendo da técnica empregada. Técnicas convencionais mostram positividade de $22 \%^{(1)}, 25 \%^{(26,34,44)}$ e $43 \%^{(8)}$, atingindo $64 \%$ com a tomografia helicoidal ${ }^{(42)}$ que, realizada em todos os pacientes desta casuística, mostrou $25 \%$ de resultado positivo na localização do insulinoma.

Após a descrição inicial da arteriografia seletiva por cateterização do tronco celíaco para o diagnóstico de insulinoma ${ }^{(3,33)}$, a localização pré-operatória desta neoplasia melhorou consideravelmente, mostrando resultados positivos em cerca de $70 \%{ }^{(43)}$ e de $80 \%{ }^{(15)}$; em nosso meio, foram observados resultados de $40 \%{ }^{(1)}$, até $54 \%^{(26)}$ na localização do insulinoma.

Neste estudo, a arteriografia foi realizada em nove pacientes, com resultados positivos em apenas dois $(22,2 \%)$. As dosagens seriadas de insulina no sistema portal, apesar de sua alta positividade na localização topográfica dos insulinomas ${ }^{(47)}$, é método sujeito a complicações e até mesmo a morte ${ }^{(4)}$. Contudo é considerado, na atualidade, o melhor recurso propedêutico visando a localização dos insulinomas ${ }^{(26,34,47)}$.

Não obstante a utilização dos métodos de diagnóstico anteriormente mencionados, aproximadamente $20 \%$ dos insulinomas podem não ser localizados na fase pré-operatória ${ }^{(18)}$. Para estes, reserva-se a da ultra-sonografia intra-operatória, que permite a localização das lesões com índices superiores a $95 \%^{(5,6,38,41)}$. Este recurso associado à palpação intra-operatória permite a identificação de até $100 \%$ dos insulinomas ${ }^{(17,54)}$. Graças a este recurso têm-se abandonado as ressecções pancreáticas às cegas, sendo essa associação o melhor método de localização dos insulinomas ${ }^{(6)}$. O ultrasom intra-operatório foi empregado em três dos doentes desta série, logrando identificar a lesão em todos. Embora os insulinomas tivessem sua localização definida no pré-operatório, em apenas sete doentes desta casuística, a identificação das lesões foi possível em todos durante o ato operatório. Recentes avanços na investigação pré-operatória dos insulinomas têm sido referidos nos últimos anos. Destaca-se a ecoendoscopia, com resultados positivos de mais de
$90 \%{ }^{(36,40)}$; este método foi empregado com sucesso em três doentes da presente casuística.

A exposição ampla do pâncreas mediante a abertura do ligamento gastrocólico e a manobra de Kocher são procedimentos indispensáveis durante a cirurgia ${ }^{(48)}$ e foram realizados rotineiramente nos doentes desta série, permitindo a visibilização e palpação de todas as lesões.

No que diz respeito à distribuição das lesões no pâncreas, alguns dados merecem consideração. Trabalhos iniciais ${ }^{(48)}$ mostram maior incidência no corpo e cauda do pâncreas; posteriormente esta distribuição se fez notar, de maneira uniforme, entre a cabeça, corpo e cauda do órgão ${ }^{(22,39,43,50)}$. A localização extrapancreática dos insulinomas oscila entre $1 \%$ e $2 \%{ }^{(43)}$. Na presente série a localização das lesões fez-se predominantemente no corpo e cauda $(80,7 \%)$, sendo $18,7 \%$ de situação cefálica.

Embora a literatura afirme, de maneira quase unânime, que os insulinomas são únicos entre $80 \%$ e $90 \%$ das vezes, restando, portanto, $10 \%$ a $20 \%$ de insulinomas múltiplos ${ }^{(22,26,43)}$, estes achados revelaram $66,6 \%$ de neoplasias únicas e 33,3\% de neoplasias múltiplas, fato atribuído ao reduzido número de doentes analisados.

A indicação cirúrgica em doentes com hipoglicemia orgânica baseiase nos seguintes fatos: a) ingestão contínua de hidratos de carbono que levaria à obesidade, por vezes mórbida, dificultando posteriormente o procedimento cirúrgico; b) hipoglicemias severas e repetidas, que provocariam deterioração corticocerebral irreversível, chegando mesmo a estados demenciais ou seqüelas neurológicas que exigem internações repetidas ou definitivas, mesmo após a cura cirúrgica da hipoglicemia; c) desconhecimento da natureza histopatológica da lesão ${ }^{(50)}$. A maioria dos serviços tem utilizado, além de administração de soluções glicosadas, a monitorização intra-operatória da glicemia $^{(28)}$, recurso que, além de proteger o doente, orienta e caracteriza a remoção da lesão e o sucesso do procedimento ${ }^{(19)}$. A hiperglicemia, após remoção do insulinoma, foi observada em $91,6 \%$ dos doentes que compõem esta casuística.

A enucleação é o procedimento mais citado em grandes casuísticas $^{(22,43,50)}$, com maior indicação nos casos de lesões únicas, superficiais e, principalmente, localizadas na cabeça do pâncreas ${ }^{(26)}$. Este método deve ser abandonado em se tratando de insulinoma maligno. Nesta casuística a enucleação como procedimento único foi realizada em quatro doentes: em três destes, a lesão situava-se na porção cefálica do pâncreas, e em um localizava-se no corpo. Num doente submetido a pancreatectomia caudal, onde se localizava um insulinoma, a enucleação foi empregada para remover um segundo insulinoma localizado no corpo do pâncreas. Como outra opção cirúrgica no tratamento dos insulinomas, temos as ressecções pancreáticas, procedimento de escolha para lesões de localização caudal $^{(43)}$, profundas ${ }^{(26)}$, na microadenomatose do pâncreas e nas lesões malignas ${ }^{(26,43)}$. Este procedimento foi realizado em $66,6 \%$ de nossos pacientes. 
Grandes séries ${ }^{(19,26,43)}$ observaram maior incidência de complicações pós-operatórias, notadamente fístulas e pseudocistos, naqueles submetidos a enucleação. A fístula pancreática é, sem dúvida, a mais freqüente destas complicações ${ }^{(19,26,29,34,37,43,44,48,53)}$ e parece estar relacionada ao tipo de cirurgia realizada, sendo habitualmente de evolução favorável ${ }^{(26,43)}$. Esses achados coincidem com aqueles observados na presente série (58,3\%), sendo em quatro deles $(57,2 \%)$ após ressecção pancreática e em três $(42,8 \%)$ após enucleação, todos de evolução favorável. A pancreatite aguda ${ }^{(21,39)}$, o pseudocisto de pâncreas ${ }^{(43,44,53)}$, também complicações dessa cirurgia, não foram observadas nesta série. Menos freqüentes, porém importantes por sua gravidade e necessitando de reintervenções, são as coleções purulentas intracavitárias ${ }^{(39)}$ observadas em um dos doentes.

A hiperglicemia observada no pós-operatório imediato e nos primeiros dias que seguem à cirurgia é considerada fisiológica ${ }^{(43)}$. Sua reversão, com estabilização da glicemia em níveis normais, faz desta ocorrência fato passageiro, recebendo por alguns a denominação de hiperglicemia transitória ${ }^{(18)}$. Sua persistência, em níveis patológicos, define a ocorrência do diabetes mellitus, complicação considerada freqüente por alguns autores ${ }^{(19,39,45)}$. Este quadro foi observado em dois $(16,6 \%)$ doentes desta casuística, ambos submetidos a pancreatectomia e controlados com hipoglicemiante oral. Quando analisadas a enucleação versus pancreatectomia, observa-se vantagem discreta da primeira, embora o número de doentes não permita conclusão no que se refere à fístula e ao diabetes.

O desaparecimento dos sintomas de hipoglicemia, a normalização dos níveis de glicemia, bem como a confirmação histopatológica da lesão ${ }^{(11)}$, critérios utilizados para caracterizar a cura dos doentes portadores de insulinoma após ressecção cirúrgica, foram observados em todos os doentes da casuística presente. Acompanhados por períodos que variaram de 2 a 96 meses, com média de 43 meses, não se observou recidiva dos sintomas em nenhum dos 11 doentes portadores de insulinoma benigno. Um doente com insulinoma maligno e metástase ganglionar teve recidiva dos sintomas, bem como hipoglicemia e hiperinsulinismo 1 ano e meio após a cirurgia.

$\mathrm{O}$ estudo imunohistoquímico dos insulinomas ${ }^{(23,24,25)}$ permite caracterizar melhor essas neoplasias, evidenciando que a maioria dos tumores endócrinos do pâncreas produz mais de um hormônio. Embora a microscopia eletrônica forneça dados ultra-estruturais dos insulinomas, a imunohistoquímica, além de permitir realizar estudo retrospectivo de lesões fixadas em parafina, constitui-se no método de escolha para o estudo das neoplasias endócrinas do pâncreas ${ }^{(30)}$. Na série em discussão, verificou-se que $83,3 \%$ dos pacientes com diagnóstico clínico de insulinoma, eram portadores de tumores produtores de dois ou mais hormônios.

Analisando dados da literatura e desta série, pode-se concluir que o tratamento cirúrgico permitiu a reversão dos quadros clínico e laboratorial nos doentes portadores de insulinoma do pâncreas.

Apodaca-Torrez FR, Triviño T, Lobo EJ, Goldenberg A, Figueira A. Pancreatic insulinomas: diagnosis and treatment. Arq Gastroenterol 2003;40(2):73-79.

ABSTRACT - Background - Despite its rarity, the insulinoma is the most common pancreatic neuroendocrine tumor. Objective - Analyze clinical and immunohistochemical data from surgical resection of the pancreas insulinoma. Method - Twelve cases are described, concerning surgical aspects, complications and medium-long term outcome of patients. They underwent surgical treatment due to clinical suspicion and biochemical diagnosis of hypoglycemia and hyperinsulinism. Results - The insulinoma was identified preoperatively in seven patients, while intraoperative ultrasonography and palpation were necessary for diagnosis in the other cases. Eight patients underwent pancreatic resection and pancreatic leak was observed in seven cases. Two patients developed diabetes mellitus and no mortality occurred in the current series. Conclusion - All patients presented satisfactory outcome and remained asymptomatic with normal glicemia levels.

HEADINGS - Insulinoma, surgery. Pancreatic neoplasms.

\section{REFERÊNCIAS BIBLIOGRÁFICAS}

1. Abath CGC. Localização da fonte de hiperinsulinismo através dos métodos de imagem. Rev Imagem 1990;12:1-8.

2. Artigas GV, Brenner S, Campos ACL, Niclewicz ED. Insulinomas: aspectos clínicos e cirúrgicos. Rev Med Paraná 1985;43:61-4.

3. Bookstein JJ, Oberman HA. Appraisal of selective angiography in localizing islet-cell tumors of the pancreas. Radiology 1966;86:682-4

4. Böttger TC, Junginger T. Is preoperative radiographic of islet cell tumors in patients with insulinoma necessary? World J Surg 1993;17:427-32.

5. Charboneau JW, James EM, Van Herden JA, Grant CS, Sheedy PF. Intraoperative real-time ultrasonographic localization of pancreatic insulinoma: initial experience. J Ultrasound Med 1983;2:251-4.

6. Correnti S, Liverani A, Antonini G, Paganelli MT, Mercati U. Intraoperative ultrasonography for pancreatic insulinomas. Hepatogastroenterology 1996;43:207-11
7. Crain EL Jr, Thorn GW. Functioning pancreatic islet cell adenomas: a review of the literature and presentation of two new diferential tests. Medicine (Baltimore) 1949;28:427-47.

8. Dunnick NR, Long JA, Krudy A, Shawker TH, Doppman JL. Localizing insulinomas with combined radiographic methods. AJR Am J Roentgenol 1980;135:747-52.

9. Fajans SS, Floyd JC. Diagnosis and medical management of insulinomas. Annu Rev Med 1979;30:313-29.

10. Fedorak IJ, Ko TC, Gordon D, Flisak M, Prinz RA. Localization of islet cell tumors of the pancreas: a review of current techniques. Surgery 1993;113:242-9.

11. Frantz VK. Tumor of islet cells with hyperinsulinism; benign, malignant, and questionable. Ann Surg 1940;112:161-76.

12. Galbut DL, Markowitz AM. Insulinoma: diagnosis, surgical management and long-term follow-up. Am J Surg 1980;139:682-90.

13. Galiber AK, Reading CC, Charboneau JW, Sheedy PF, James EM, Gorman B, Grant CS, Van Heerden JA, Telander RL. Localization of pancreatic insulinoma: comparison of pre- and intraoperative ultra-sonography with CT and angiography. Radiology 1988;166:405-8 
14. Goffi FS, Bromberg S, Reis LC, Neves DP, Almeida LA, Guimarães JS, Hashiba K. Neoplasias insulares do pâncreas. Rev Assoc Med Bras 1975;21:67-71.

15. Gray RK, Rösch J, Grollman JH. Arteriography in the diagnosis of islet-cell tumors. Radiology 1970;97:39-44.

16. Grosfeld JL, Vane DW, Rescorla FJ, McGuire W, West KW. Pancreatic tumors in childhood: analysis of 13 cases. J Pediatr Surg 1990;25:1057-62.

17. Huai JC, Zhang W, Niu HO, Su ZX, McNamara JJ, Machi J. Localization and surgical treatment of pancreatic insulinomas guided by intraoperative ultrasound. Am J Surg 1998;175:18-21.

18. Kaplan EL, Lee ChH. Recent advances in the diagnosis and treatment of insulinomas. Surg Clin North Am 1979;59:119-29.

19. Kavlie H, White TT. Pancreatic islet beta cell tumors and hyperplasia: experience in 14 Seattle hospitals. Ann Surg 1972;175:326-35.

20. King CM, Reznek RH, Dacie JE, Wass JAH. Review. Imaging islet cell tumours. Clin Radiol 1994;49:295-303.

21. Kuzin NM, Egorov AV, Kondrashin, AS, Lotov NA, Kuznetzov NS, Majorova JB. Preoperative and intraoperative topographic diagnosis of insulinomas. World J Surg 1998;22:593-8.

22. Laroche GP, Ferris DO, Priestley JT, Scholz DA, Dockerty MB. Hyperinsulinism. Arch Surg 1968;96:763-72.

23. Larson LI, Grimelius L, Hakanson R, Rehfeld JF, Stadil F, Holst J, Angervall L, Sundler F. Mixed endocrine pancreatic tumors producing several peptide hormones. Am J Pathol 1975;79:271-84.

24. Liu T, Tseng H, Zhu Y, Zhong S, Chen J, Cui Q. Insulinoma. An immunocytochemical and morphologic analysis of 95 cases. Cancer 1985;56:1420-9.

25. Liu TH, Zhu Y, Cui QC, Cai LX, Ye SF, Zhong SX, Jia HP. Nonfunctioning pancreatic endocrine tumors. An immunohistochemical and electron microscopic analysis of 26 cases. Pathol Res Pract 1992;188:191-8.

26. Machado MCC, Jukemura J, Cunha JEM, Penteado S, Bacchella T, Abdo EE, Montagnini A, Herman P, Machado MAC, Pinotti HW. Tratamento cirúrgico dos insulinomas - estudo de 59 casos. Rev Assoc Med Bras 1998;44:159-66.

27. Mann JR, Rayner PHW, Gourevitch A. Insulinoma in childhood. Arch Dis Child 1969;44:435-42.

28. McMillan FL, Scheibe JR. Islet cell tumor of the pancreas. Am J Surg 1951;82:759-61.

29. Menegaux F, Schmitt G, Mercadier M, Chigot JP. Pancreatic insulinomas. Am J Surg 1993;165:243-8.

30. Mukai K, Greider MH, Grotting JC, Rosai J. Retrospective study of 77 pancreatic endocrine tumors using the immunoperoxidase method. Am J Surg Pathol 1982;6:387-99.

31. Nicholls AG. Simple adenoma of the pancreas arising from an island of Langerhans. J Med Res 1902;8:385-95.

32. Niclewicz ED'a, Kastrup M, Hungria de Camargo LA, Suplicy HL, LacerdaFilho L, Maciel L, Cortes AB, Graf R, Artigas GV. Insulinomas: aspectos clínicos e terapêuticos. Arq Bras Endocrinol Metabol 1979;23:36-46.

33. Olsson O. Angiographic diagnosis of an islet cell tumor of the pancreas. Acta Chir Scand 1963;126:346-51.

34. Pasieka JL, McLeod MK, Thompson NW, Burney RE. Surgical approach to insulinomas. Arch Surg 1995;127:442-7.

35. Pedrazzoli S, Pasquali C, D'andrea AA. Surgical treatment of insulinoma. Br J Surg 1994;81:672-6.
36. Pitre J, Soubrane O, Palazzo L, Chapuis Y. Endoscopic ultrasonography for the preoperative localization of insulinomas. Pancreas 1996;13:55-60.

37. Rothmund M, Angelini L, Brunt M, Farndon JR, Geelhoed G, Grama D, Herfarth C, Kaplan E, Largiader F, Morino F, Peiper HJ, Proye Ch, Röher K, Kümmerle F, Thompson NW, Van Heerden JA. Surgery for benign insulinoma: an international review. World J Surg 1990;14:393-9.

38. Rueckert K, Klotter HJ, Kümmerle F. Intraoperative ultrasonic localization of endocrine tumors of the pancreas. Surgery 1984;96:1045-7.

39. Shatney $\mathrm{CH}$, Grage TB. Diagnostic and surgical aspects of nsulinoma: a review of twenty seven cases. Am J Surg 1974; 127:174-84.

40. Shumacher B, Lübke HJ, Frieling T, Strohmeyer G, Starke AAR. Prospective study on the detection of insulinomas by endoscopic ultrasonography. Endoscopy 1996;28:273-6.

41. Sigel B, Duarte B, Coelho JCU, Nyhus LM, Baker RJ, Machi J. Localization of insulinomas of the pancreas at operation by real time ultrasound scanning. Surg Gynecol Obstet 1983;156:145-7.

42. Stark DD, Moss AA, Goldberg HI, Deveney CW, Way L. Computed tomography and nuclear magnetic resonance imaging of pancreatic islet cell tumors. Surgery 1983;94:1024-7.

43. Stefanini P, Carboni M, Patrassi N, Basoli A. Beta-islet cell tumors of the pancreas: results of a study on 1067 cases. Surgery 1974;75:597-609.

44. Stipa V, Chirletti P, Caronna R. Stratégie diagnostique et thérapeutique des insulinomes. A propos d'une expérience personnelle de 21 cas. Chirurgie 1996;121:667-71.

45. Thompson GB, Service FJ, Van Heerden JA, Carney JA, Charboneau W, O'Brien PC, Grant CS. Reoperative insulinomas, 1927 to 1992: an institutional experience. Surgery 1993;114:1196-206.

46. Vea H, Trovik TS, Sager G, Birkeland K, Revhaug A, Sundsfjord J, Jorde R. Return of beta-adrenergic sensitivity in a patient with insulinoma after removal of the tumour. Diabet Med 1997;14:979-84.

47. Vinik AI, Delbridge L, Moattari R, Cho K, Thompson N. Transhepatic portal vein catheterization for localization of insulinomas: a ten year experience. Surgery 1991;109:1-11.

48. Whipple AO, Frantz VK. Adenoma of islet cells with hyperinsulinism. Ann Surg 1935; 101:1299-329.

49. Whipple AO. The surgical therapy of hyperinsulinism. J Int Chir 1938;3:23776.

50. Whipple AO. Hyperinsulinism in relation to pancreatic tumors. Surgery 1944;16:289-305.

51. Wilder RM, Allan FN, Power MH, Robertson HE. Carcinoma of the islands of the pancreas. JAMA 1927;89:348-55.

52. Yallow RS, Berson AS. Immunoassay of endogenous plasma insulin in man. J Clin Invest 1960;89:1157-75.

53. Yau Lo Ch, Lam KY, Kung AWC, Lam KSLL, Tung PHM, Fan ST. Pancreatic insulinomas. A 15 year experience. Arch Surg 1997;132:926-30.

54. Zeiger MA, Shawker TH, Norton JA. Use of intraoperative ultrasonography to localize islet cell tumors. World J Surg 1993;17:448-54.

Recebido em 20/6/2002. Aprovado em 26/11/2002. 